\title{
CELL SURFACE THY-1-CROSS-REACTIVE GLYCOPROTEIN IN CULTURED PC12 CELLS: MODULATION BY NERVE GROWTH FACTOR AND ASSOCIATION WITH THE CYTOSKELETON ${ }^{1}$
}

\author{
CHRISTIANE RICHTER-LANDSBERG,${ }^{*} \ddagger$ LLOYD A. GREENE $\ddagger^{2}$ AND MICHAEL L. SHELANSKI $\ddagger$
}

${ }^{*}$ Department of Biology, University of Bremen, 2800 Bremen 33, Federal Republic of Germany, and $\$$ Department of Pharmacology, New York University Medical Center, New York, New York 10016

Received May 14, 1984; Revised July 23, 1984; Accepted August 8, 1984

\begin{abstract}
In cultured PC12 rat pheochromocytoma cells, nerve growth factor (NGF) selectively stimulated the incorporation of $\left[{ }^{3} \mathrm{H}\right]$ fucose into a glycoprotein of apparent $M_{\mathrm{r}} \approx 25,000$, as determined by sodium dodecyl sulfate-gel electrophoresis. Neither dibutyryl cyclic adenosine $3^{\prime}: 5^{\prime}$-monophosphate nor epidermal growth factor mimicked this effect. Using gradient gels, the affected protein was resolved into two closely migrating bands. Enhancement of labeling was present by 1 to 2 days of treatment with NGF and was maximal after 4 to 7 days. Short-term extraction of PC12 cell monolayer cultures with Triton X-100 left the 25,000-dalton glycoprotein associated with the detergent-resistant cytoskeletal fraction. The $M_{\mathrm{r}} \approx 25,000$ glycoprotein was shown to be immunologically cross-reactive with Thy-1.1 antigen by indirect immunoprecipitation with monoclonal Thy-1.1 antibodies. Anti-Thy-1.1 labeling, as demonstrated by indirect immunofluorescence, was distributed on PC12 cell bodies and along neuritic processes and remained attached to the cytoskeleton as part of the surface lamina of cells treated and untreated with NGF. The selective increase of the $M_{\mathrm{r}} \approx 25,000$ glycoprotein in NGF-treated cultures was also paralleled by increases in material immunoprecipitated from fucose-labeled cells with anti Thy-1.1 monoclonal antibodies.

Immunoprecipitations with extracts of $\left[{ }^{35} \mathrm{~S}\right]$ methionine-labeled cultures indicated that NGF causes an increase in synthesis, rather than merely glycosylation, of the 25,000-dalton/Thy-1-cross-reactive protein. The effect of NGF on this protein was blocked by inhibitors of RNA synthesis, suggesting involvement of a transcription-dependent mechanism. The data presented here indicate that a Thy-1-cross-reactive glycoprotein is increased during NGF-promoted neuronal differentiation and are consistent with a possible role for this component in neuronal development and function.
\end{abstract}

Nerve growth factor (NGF) is a polypeptide participating in the development and maintenance of certain neural crest derivatives, e.g., embryonic sensory neurons and sympathetic neurons (Levi-Montalcini and Angeletti, 1968; Barde and Thoenen, 1980; Greene and Shooter, 1980). The clonal cell line PC12, which has been derived from a transplantable rat pheochromocytoma (Greene and Tischler, 1976), responds to NGF by acquiring many properties of sympathetic neurons, and, thus, has become a useful model system for studies of neuronal differentiation and of the mechanism of action of NGF (Greenc and Tischler, 1976, 1982).

Neuronal differentiation is often accompanied by cell surface modulation, and cell surface glycoproteins in particular are thought to participate in the development of neuronal functions, such as synapse formation and neurite outgrowth (cf. Barondes, 1976). Therefore it has been of particular interest to identify changes in the glycoprotein composition of $\mathrm{PC} 12$ cells

\footnotetext{
${ }^{1}$ This work was supported by United States Public Health Service Grants NS 15076, NS 16036, and NS 16839, by the McKnight Foundation, and by Deutsche Forschungsgemeinschaft Grant RI 384 2-1. We thank Dr. R. J. Morris for helpful advice. L. A. G. is a Career Development Awardee of the Irma T. Hirschl Trust.

${ }^{2}$ To whom correspondence should be addressed.
}

that accompany NGF-induced neuronal differentiation. It has been shown that NGF selectively elevates the specific levels in PC12 cells of a high molecular weight $\left(M_{\mathrm{r}} \approx 230,000\right)$ surface glycoprotein designated the NGF-inducible large external (NILE) glycoprotein (McGuire el al., 1978; Salton et al., 1983). This species has been found to be a neuronal marker (Salton et al., 1983). In addition, NGF selectively increases the labeling of a low molecular weight (apparent $M_{\mathrm{r}} \approx 25,000$ ) glycoprotein in PC12 cultures (McGuire et al., 1978). The present communication further characterizes and describes the effect of NGF on the $M_{\mathrm{r}} \approx 25,000$ species. It is shown that this glycoprotein is a constitutent of the surface lamina of PC12 cells and as such is associated with the detergent-resistant cytoskeleton. Data are also presented showing that the $M_{\mathrm{r}} \approx 25,000$ glycoprotein is immunologically cross-reactive with the cell surface antigen Thy-1, a glycoprotein present in relatively large amounts on thymocytes and on brain cells (Mirsky and Thompson, 1975; Williams et al., 1975; Barclay et al., 1976; Williams and Gagnon, 1982).

\section{Materials and Methods}

Materials. Tissue culture media were from either $\mathrm{KC}$ Biological (Lenexa, KA) or Boehringer-Mannheim (Mannheim, Federal Republic of Germany). [6- $\left.{ }^{3} \mathrm{H}\right]$ Fucose $(12 \mathrm{Ci} / \mathrm{mmol})$ and $\left[{ }^{35} \mathrm{~S}\right]$ methionine $(1212$ 
$\mathrm{Ci} / \mathrm{mmol}$ ) were from New England Nuclear (Boston, MA), and ${ }^{14} \mathrm{C}$ labeled protein molecular weight standards were from Bethesda Research Laboratories (Gaithersburg, MD). The molecular weights of these were as follows: cytochrome $c, 12,300 ; \beta$-lactoglobulin, 18,400; chymotrypsinogen, 25,700; ovalbumin, 43,000; bovine serum albumin, 68,000 ; phosphorylase B, 92,500; myosin (H-chain), 200,000. Mouse IgG antibody against rat Thy-1.1, clone OX7 (MAS 027c), was from Sera-Lab (Crawley, England). Fluorescein isothiocyanate (FITC)-conjugated goat anti-mouse IgG and FITC-conjugated lentil lectin were from Miles Laboratories (Elkhardt, IN), and protein A-Sepharose was from Pharmacia (Piscataway, NJ).

Cell culture. PC12 cells were cultured as previously described (Greene and Tischler, 1976, 1982) on collagen-coated plastic culture dishes with or without $50 \mathrm{ng} / \mathrm{ml}$ of NGF (Mobley et al., 1976) in complete medium (85\% Roswell Park Memorial Institute medium 1640, 10\% horse serum, $5 \%$ fetal calf serum).

Labeling of cells. Proteins were labeled by incubating the cells for 72 $\mathrm{hr}$ in complete medium containing $\left[\mathrm{L}-6{ }^{3} \mathrm{H}\right]$ fucose $(10 \mu \mathrm{Ci} / \mathrm{ml})$ or $\left[{ }^{35} \mathrm{~S}\right]$ methionine $(100 \mu \mathrm{Ci} / \mathrm{ml})$ or by incubation for $4 \mathrm{hr}$ with $100 \mu \mathrm{Ci} / \mathrm{ml}$ of $\left[{ }^{35} \mathrm{~S}\right]$ methionine in methionine-free medium. In some experiments, cultures were prelabeled with $\left[{ }^{3} \mathrm{H}\right]$ fucose for $48 \mathrm{hr}$ before treatment with NGF.

Trypsinization. Mild trypsinization to remove surface-exposed components was carried out as previously described (McGuire et al., 1978).

Soluble and particulate fractions. Soluble cytoplasmic proteins were isolated as described elsewhere (Truding et al., 1974). Briefly, labeled cells were washed three times with phosphate-buffered saline (PBS) and removed from the culture dish by gentle trituration. Cells were broken by sonication and centrifuged for $10 \mathrm{~min}$ at $2,000 \times g$ to remove nuclei. The supernatant was recentrifuged at $100,000 \times g$ for $90 \mathrm{~min}$. The particulate fraction was dissolved in sample buffer for SDS-PAGE. The high speed supernatant, constituting the cytoplasmic soluble protein fraction, was dialyzed against PBS, concentrated by lyophilization, and dissolved in sample buffer.

Cytoskeletal fractions. Cellular monolayers were washed with PBS three times. Following this, $1 \mathrm{ml}$ (per 35-mm dish) of extraction buffer $(0.05 \mathrm{M} \mathrm{NaCl}, 0.01 \mathrm{~m}$ HEPES ( $\mathrm{pH} 7.4), 2.5 \mathrm{mM} \mathrm{MgCl}_{2}, 0.3 \mathrm{M}$ sucrose, and $1 \mathrm{mM}$ phenylmethanesulfonyl fluoride) containing $0.5 \%$ Triton $\mathrm{X}$ $100(\mathrm{v} / \mathrm{v})$ was added (Ben-Ze'ev et al., 1979). Cells were incubated for either $2 \mathrm{~min}$ on ice or $5 \mathrm{~min}$ at $37^{\circ} \mathrm{C}$. The plates were washed twice with extraction buffer and the residue containing the cytoskeletal fraction was dissolved in $50 \mu \mathrm{l}$ of sample buffer for SDS-PAGE.

Nuclear fraction. Cells were lysed in a buffer containing $0.5 \%$ Nonidet P-40, $10 \mathrm{~mm}$ Tris ( $\mathrm{pH} 7.5$ ), $3 \mathrm{mM} \mathrm{MgCl}, 10 \mathrm{mM} \mathrm{NaCl}$, and kept on ice for $10 \mathrm{~min}$. The homogenate was centrifuged at $300 \times g$ for 10 min. The pellet was resuspended in the same buffer and treated as above three times. The isolation procedure was monitored by phase microscopy and the final nuclear pellet was dissolved in sample buffer for subsequent gel electrophoresis.

Immunoprecipitation. For immunoprecipitation, $\left[{ }^{3} \mathrm{H}\right]$ fucose-labeled PC12 cells ( \pm NGF treatment) were extracted in Tris-Cl buffer $(50 \mathrm{~mm}$, pH 6.8) containing $2 \%$ Triton X-100 for $30 \mathrm{~min}$ on ice. The cell extract was centrifuged at $100,000 \times g$ for $30 \mathrm{~min}$. Indirect immunoprecipitation was carried out according to the method of Goldman and Blobel (1978) with some modifications. Aliquots of 50,000 trichloroacetic acid (TCA)precipitable $\left[{ }^{3} \mathrm{H}\right]$ fucose cpm or 200,000 TCA-precipitable $\left[{ }^{35} \mathrm{~S}\right]$ methionine cpm were diluted to $200 \mu \mathrm{l}$ with Tris buffer $(50 \mathrm{mM}, \mathrm{pH} 6.8)$. AntiThy-1.1 antiserum $(0.1$ to $1.0 \mu \mathrm{l})$ was added and samples were gently agitated for $16 \mathrm{hr}$ at $4^{\circ} \mathrm{C}$. To precipitate the antigen-antibody complexes, $5 \mathrm{mg} /$ aliquot of preswollen protein A-Sepharose were added for $2 \mathrm{hr}$ at room temperature. The precipitates were washed three times with PBS containing $1 \%$ Triton X-100 and then boiled for $5 \mathrm{~min}$ in 80 $\mu \mathrm{l}$ of sample buffer each. The samples were centrifuged and the supernatant of each was subjected to PAGE.

$S D S-P A G E$. For gel-electrophoretic analysis, cellular monolayers were washed with PBS three times and dissolved in sample buffer $(100$ $\mu \mathrm{l} / 35-\mathrm{mm}$ dish) containing $10 \%$ glycerol, $1 \% 2$-mercaptoethanol, $1 \%$ SDS, mM Tris (pH 6.8). Samples were treated for $1 \mathrm{~min}$ at $100^{\circ} \mathrm{C}$. Aliquots were loaded onto 7.5 to $15 \%$ or 5 to $15 \%$ gradient acrylamide slab gels and separated in an SDS-containing buffer system as described by Laemmli (1970). Unless otherwise specified, 10,000 TCA-precipitable cpm were loaded/lane. For molecular weight determinations, a mixture (described above) of ${ }^{14} \mathrm{C}$-methylated marker proteins with molecular weights in the range of 12,000 to 200,000 was treated as above and applied to the gels.
Autoradiography. Fluorography was carried out by permeating the gels with dimethylsulfoxide and 2,5-diphenyloxazole (Laskey and Mills, 1975). The gels were vacuum dried on Whatman no. 3 MM filter papers and exposed at $-70^{\circ} \mathrm{C}$ to Kodak X-R-5 $\mathrm{x}$-ray films for 1 to 3 weeks.

Indirect immunofluorescence. For fluorescent staining, PC12 cells were grown on polylysine-coated coverslips for 3 to 6 days in the presence or absence of NGF. Cells were washed three times with PBS, and then anti-Thy-1.1 antibodies at a dilution of 1:100 were added for $30 \mathrm{~min}$ at room temperature. After washing three times with PBS, cells were incubated for another $30 \mathrm{~min}$ at room temperature with FITCconjugated goat anti-mouse IgG at a dilution of 1:100. Cells were washed three times with PBS and fixed in $1 \%$ paraformaldehyde in PBS. For staining of the surface lamina, cells were treated with lysis buffer containing $0.5 \%$ Triton $\mathrm{X}-100$ for 1 min before fixation. Control experiments were carried out with nonimmunized mouse IgG. Fluorescent labeling was monitored using a Zeiss epifluorescence microscope.

Fluorescent lentil lectin labeling. Monolayer cultures grown on polylysine-coated coverslips were washed three times with PBS and incubated for 30 min with FITC-conjugated Lens culinaris hemagglutinin B (lentil lectin) at a concentration of $50 \mu \mathrm{g} / \mathrm{ml}$ in PBS. Cells were washed extensively with PBS (three times, $10 \mathrm{~min}$ ) and then fixed in $1 \%$ paraformaldehyde in PBS and monitored as above.

\section{Results}

\section{Effect of NGF on the $M_{\mathrm{r}} \approx 25,000$ glycoprotein}

To study cellular glycoprotein composition, $\mathrm{PC} 12$ cells were labeled either in the presence or absence of NGF with $\left[{ }^{3} \mathrm{H}\right]$ fucose and analyzed by SDS-PAGE. The autoradiographs in Figures 1 and 2 illustrate the time course of the effect of NGF on the $M_{\mathrm{r}} \approx 25,000$ and other PC12 glycoproteins. In some cases, particularly with gradient gels, the $M_{\mathrm{r}} \approx 25,000$ compo-

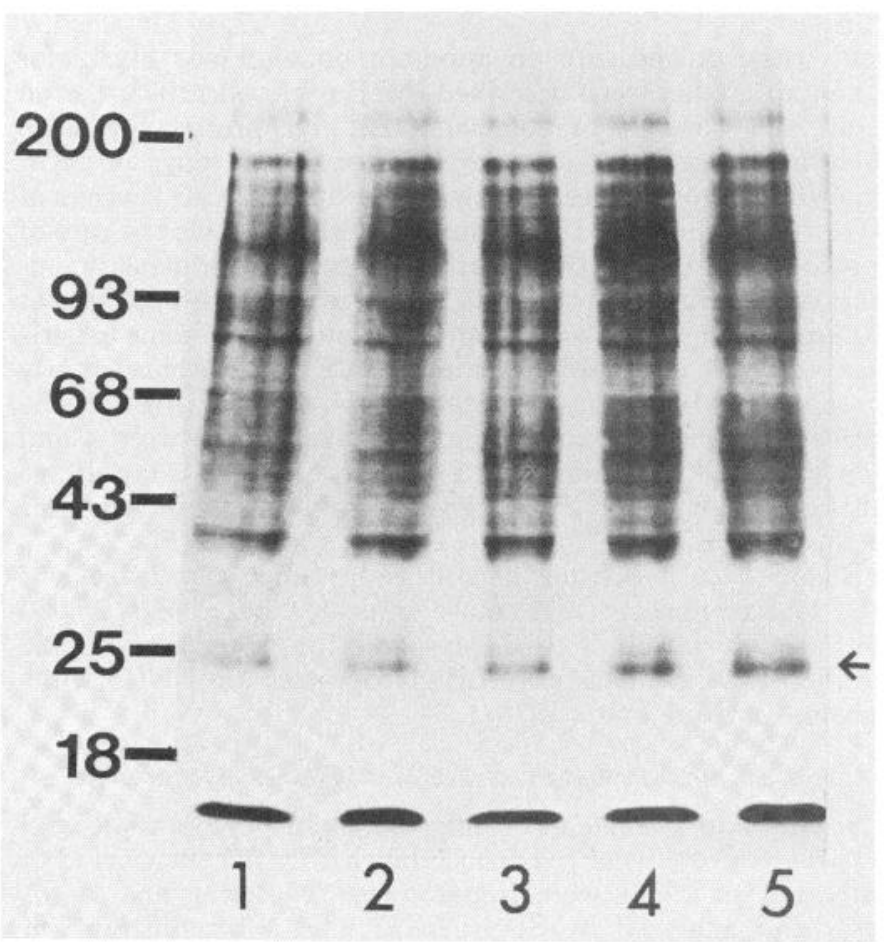

Figure 1. Time course of effects of NGF on $\left[{ }^{3} \mathrm{H}\right]$ fucose labeling of PC12 proteins: Short-term responses. Cultures were prelabeled for 48 hr with $\left[{ }^{3} \mathrm{H}\right]$ fucose and then (in the continued presence of label) exposed to $50 \mathrm{ng} / \mathrm{ml}$ of NGF for 0 (lane 1), 3 (lane 2), 6 (lane 3), 8 (lane 4), or 24 (lane 5) hr. Cells were dissolved in sample buffer and equal numbers of TCA-precipitable counts per minute were resolved and localized by SDS-PAGE and fluorography. The positions of molecular weight standards are given on the left as $M_{r}\left(\times 10^{-3}\right)$. The arrow on the right indicates the position of the NGF-responsive $M_{r} \approx 25,000$ glycoprotein. 
Figure 2. Time course of effects of NGF on $\left[{ }^{3} \mathrm{H}\right]$ fucose labeling of $\mathrm{PC} 12$ proteins: Long-term responses. Cultures were labeled by exposure to $\left[{ }^{3} \mathrm{H}\right]$ fucose for 3 days in the absence of or during the last 3 days of NGF treatment. Times of NGF exposure were 0 (lane 1), 3 (lane 2), 6 (land 3), 9 (lane 4), 13 (lane 5) 23 (lane 6), and 27 (lane 7) days. Equal numbers of TCA-precipitable counts per minute were resolved and localized by SDS-PAGE and fluorography. Numbers on the left indicate positions and apparent $M_{\mathrm{r}}\left(\times 10^{-3}\right)$ of the NILE and $M_{\mathrm{r}} \approx$ 25,000 glycoproteins.
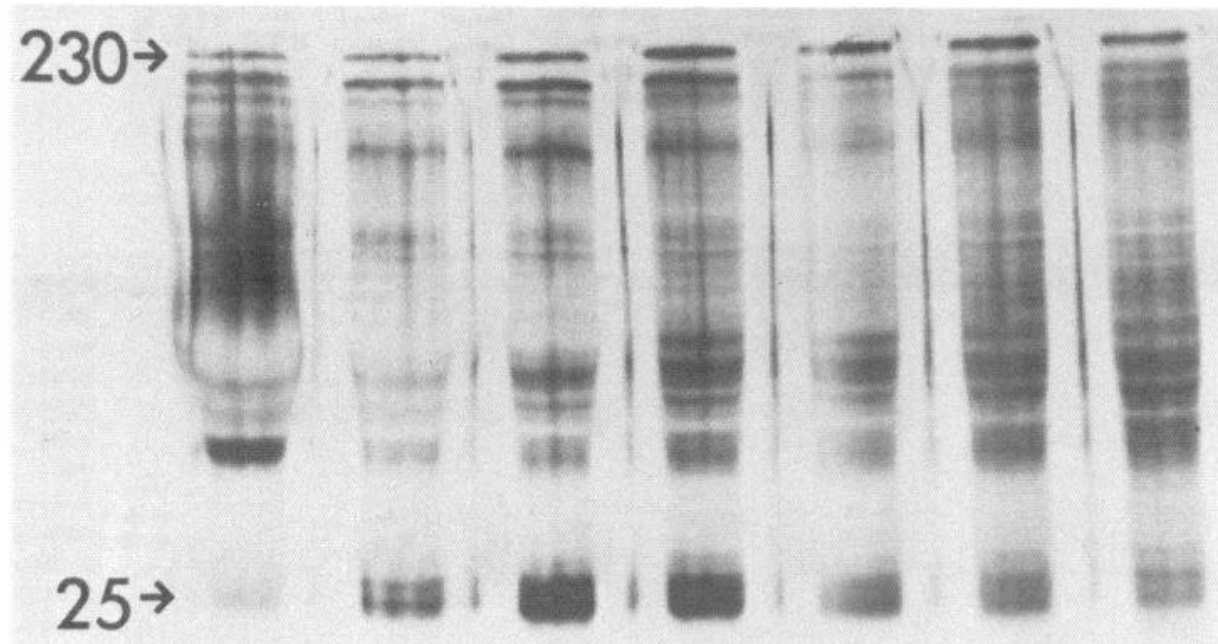
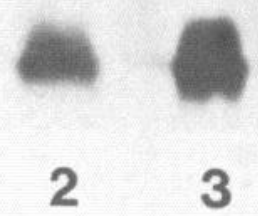

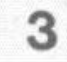

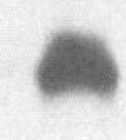

4

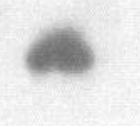

5
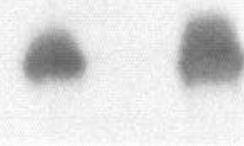

6 nent was resolved into an apparent doublet (see Fig. 2 for example). As has been described (McGuire et al., 1978; Salton et al., 1983), the $M_{\mathrm{r}} \approx 230,000$ NILE glycoprotein begins to show a change in relative levels after 2 to 3 days of NGF exposure and continues to increase for at least 1 to 2 weeks of NGF treatment. This time course roughly parallels the rate of appearance and extent of neuritic processes. In contrast, modulation of levels of the $M_{\mathrm{r}} \approx 25,000$ glycoprotein is apparent at earlier times. Enhanced labeling was apparent in some experiments as early as $8 \mathrm{hr}$ of exposure to NGF and was consistently present after 1 to 2 days of treatment with NGF (Fig. 1). The increase in labeling reached maximal levels by between 4 and 7 days of NGF treatment (Fig. 2). A partial decrease in relative labeling of the $M_{\mathrm{r}} \approx 25,000$ glycoprotein was observed after incubation with NGF for about 10 days and more (Fig. 2).

Removal of NGF from the culture medium after 2 weeks of NGF treatment caused a decrease in fucose-labeled $M_{\mathrm{r}} \approx 25,000$ glycoprotein within 3 to 6 days (Fig. 3). This time course paralleled the decrease in NILE glycoprotein after NGF withdrawal (McGuire et al., 1978).

\section{Subcellular distribution of the $M_{\mathrm{r}} \approx 25,000$ glycoprotein}

Soluble and particulate fractions. Soluble cytoplasmic and particulate proteins of $\left[{ }^{3} \mathrm{H}\right]$ fucose-labeled $\mathrm{PC} 12$ cells treated or untreated with NGF were prepared (see "Materials and Methods") and analyzed by SDS-PAGE. The autoradiograph in Figure 4 shows that only traces of the $M_{\mathrm{r}} \approx 25,000$ glycoprotein were found in the soluble fraction and that almost all of this component remained associated with the particulate fraction. Unlike NILE glycoprotein (McGuire et al., 1978), however, the $M_{\mathrm{r}} \approx 25,000$ glycoprotein was not cleaved from the cells by mild trypsinization (data not shown).

Cytoskeletal fraction. When $\left[{ }^{35} \mathrm{~S}\right]$ methionine- or $\left[{ }^{3} \mathrm{H}\right]$ fucoselabeled PC12 cells grown on collagen-coated culture dishes were gently treated with $0.5 \%$ Triton $\mathrm{X}-100$ for $5 \mathrm{~min}$ at room temperature as previously described (Ben-Ze'Ev et al., 1979), approximately $10 \%$ of the TCA-precipitable amino acid-labeled material and 3 to $5 \%$ of the TCA-precipitable sugar-labeled material remained attached to the culture dish. Examination of the extracted cultures by phase microscopy showed a nuclear monolayer surrounded by a fuzzy material (see Fig. 6). This detergent-resistant fraction, referred to as the cytoskeletal fraction, was analyzed by SDS-PAGE (Fig. 5 , lanes 1 to 4 ). The Coomassie blue-stained patterns showed several polypeptides with a 42,000-dalton band (probably actin) and a group of proteins at the lower end of the gel (probably primarily histones) as the major components (Fig. 5, lanes 1 and 2). The corresponding patterns of fucose-labeled material revealed the $M_{\mathrm{r}} \approx 25,000$ glycoprotein to be substantially enriched in the cytoskeletal fraction, particularly of NGF-treated cultures (Fig. 5 , lanes 3 and 4 ; compare, for example, to Fig. 2, lanes 1 and 4).

Nuclear fraction. Since phase microscopy of the cytoskeletal fraction showed, as expected (Osborn and Weber, 1977; BenZe'ev et al., 1979), an enrichment of nuclei, nuclear fractions were prepared from PC12 cells treated or untreated with NGF to investigate any possible association of the $M_{\mathrm{r}} \approx 25,000$ glycoprotein with the nucleus. The Coomassie blue-stained polypeptide pattern of nuclei isolated from NGF-treated PC12 cells labeled with fucose is compared to the corresponding autoradiograph in Figure 5, lanes 5 and 6 . The results demonstrate that little fucose-labeled material remains in this fraction relative to total protein (Fig. 5; compare lanes 5 and 6 with lanes 2 and 4). The small amount of sugar-labeled material that was present most probably was due to contamination of the isolated nuclei with cellular fragments that remained in the course of the isolation procedure.

\section{Response to dibutyryl cAMP and epidermal growth factor (EGF)}

Derivatives of cAMP have been reported to mimic some of the actions of NGF on PC12 cells (Schubert et al., 1978). No 

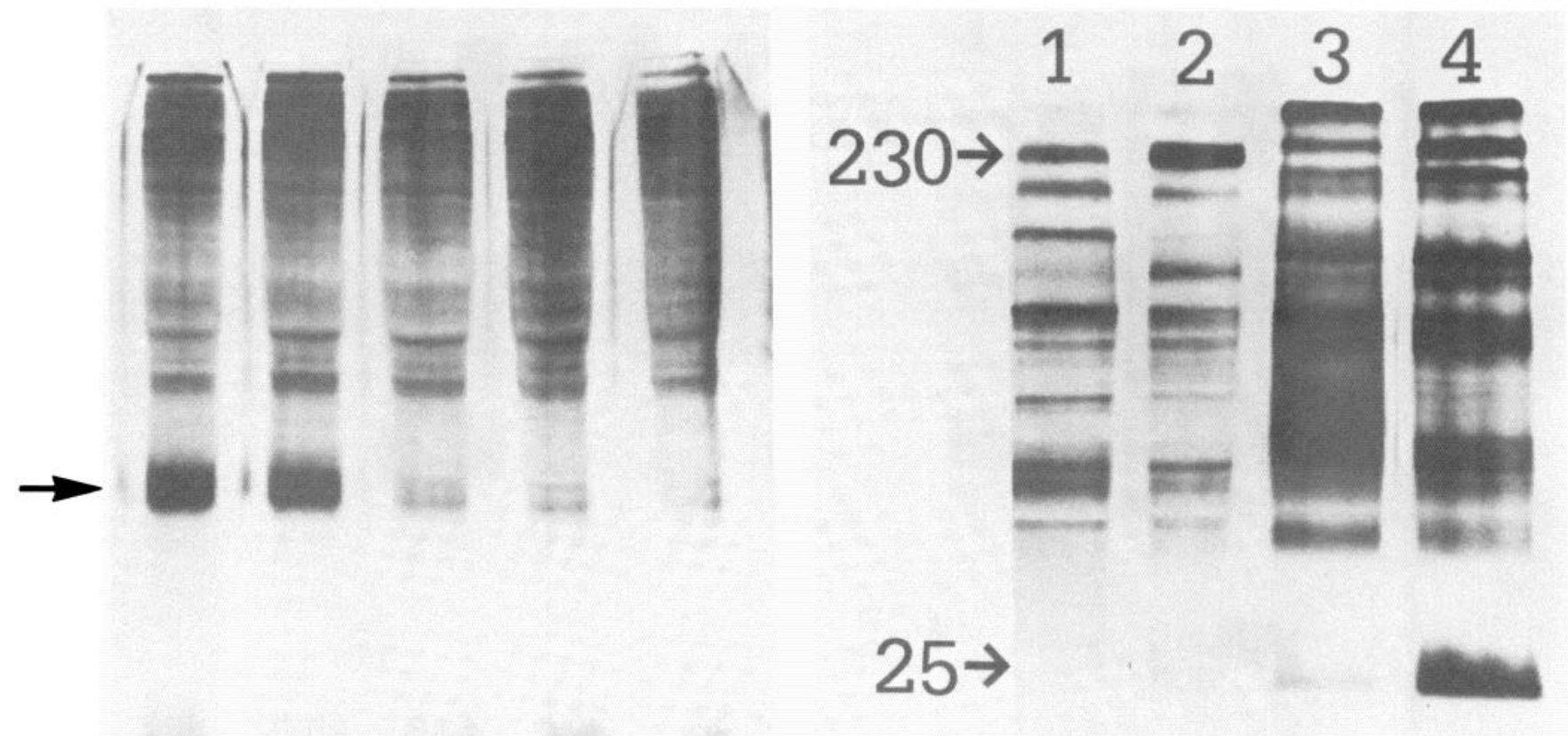

0

$$
3
$$

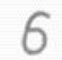

11

Figure 3. Effect of NGF withdrawal on $\left[{ }^{3} \mathrm{H}\right]$ fucose labeling of $\mathrm{PC} 12$ cell proteins. Cultures were treated with NGF for 2 weeks and then incubated in the absence of NGF for the times (days) indicated under each lane of the fluorograph. Label was present for 3 days before cultures were harvested. Equal numbers of TCA-precipitable counts per minute were resolved and localized by SDS-PAGE and fluorography. The arrow on the left indicates the position of the $M_{\mathrm{r}} \approx 25,000$ glycoprotein component.

increase in labeling of the $M_{\mathrm{r}} \approx 25,000$ glycoprotein or of other glycoproteins was observed on the SDS-PAGE patterns of PC12 cells labeled with fucose for $48 \mathrm{hr}$ to 1 week in the presence of $1 \mathrm{mM}$ dibutyryl cAMP (data not shown). The latter compound also did not affect the enhanced labeling of the $M_{\mathrm{r}}$ $\approx 25,000$ glycoprotein in response to NGF. EGF $(3 \mathrm{ng} / \mathrm{ml})$, a peptide for which PC12 cells bear receptors and to which they show certain responses in common with NGF (Huff et al., 1981 ), also failed to affect labeling of the $M_{\mathrm{r}} \approx 25,000$ glycoprotein.

\section{Evidence for the identity of the $M_{\mathrm{r}} \approx 25,000$ glycoprotein}

Thy- 1 antigen is a glycoprotein of apparent $M_{\mathrm{r}} \approx 25,000$ to 27,00 by SDS-PAGE (Barclay et al., 1976) and previously has been identified by serological methods to be present on PC12 cells (Morris et al., 1980). In the mouse, the Thy-1 molecule occurs in two allelic forms, serologically characterized as the Thy-1.1 and Thy-1.2 alloantigens, whereas in the rat only the Thy 1.1 form has been demonstrated (Williams et al., 1975; Barclay et al., 1976). The relationship between the NGFinducible $M_{\mathrm{r}} \approx 25,000$ component and the Thy-1.1 antigen was investigated by use of monoclonal anti-Thy-1.1 (clone OX7$\mathrm{HL}$ ). Specific binding of anti-Thy-1.1 is shown by living PC12 cells before and after NGF-induced differentiation, with no obvious difference in intensity (Fig. 6, $A(a$ and $b$ ) and $B(a$ and $b)$ ). Fluorescent labeling was distributed on all parts of the
Figure 4. SDS-PAGE patterns of distribution of $\left[{ }^{3} \mathrm{H}\right]$ fucose-labeled PC12 cell glycoproteins in the soluble (lanes 1 and 2) and particulate (lanes 3 and 4) fractions of control (lanes 1 and 3) and NGF-treated (lanes 2 and 4 ) cultures. Details of the fractionation are as given under "Materials and Methods." NGF-treated cultures were exposed to the factor for 1 week. Equal numbers of TCA-precipitable counts per minute were resolved and localized by SDS-PAGE and fluorography. Numbers on the left indicate positions and apparent molecular weights of the NILE and $M_{\mathrm{r}} \approx 25,000$ glycoproteins.

cells in a granular pattern. Comparison of phase and fluorescent images demonstrated that all neuronal processes were stained (Fig. 6B, $a$ and $b$ ). Patches of greater staining intensity were often observed along neurites and at growth cones. The fluorescence image of cells $( \pm N G F)$ treated with $0.5 \%$ Triton $\mathrm{X}$ 100 (i.e., cytoskeletal preparations) showed an intense staining of the remaining surface lamina (Fig. $6, A(c$ and $d)$ and $B(c$ and $d)$ ).

Since Thy-1 can be isolated by affinity chromatography using immobilized lentil lectin (Letarte-Muirhead et al., 1975), binding of FITC-labeled lentil lectin was investigated. As represented in Figure 7, $a$ and $b$, the fluorescence image of living NGF-treated PC12 cells incubated with FITC-labeled lentil lectin very much resembled the fluorescent binding pattern of cells stained with anti-Thy-1.1 (Fig. 6). Lectin-binding sites were also prominent on PC12 cells not treated with NGF (not shown) and in the cytoskeletal preparations of $\mathrm{PC} 12$ cells treated with (Fig. 7, $c$ and $d$ ) or without NGF.

The cross-reaction of Thy- 1 with the $M_{\mathrm{r}} \approx 25,000$ glycoprotein was tested by indirect immunoprecipitation. PC12 cells ( \pm 


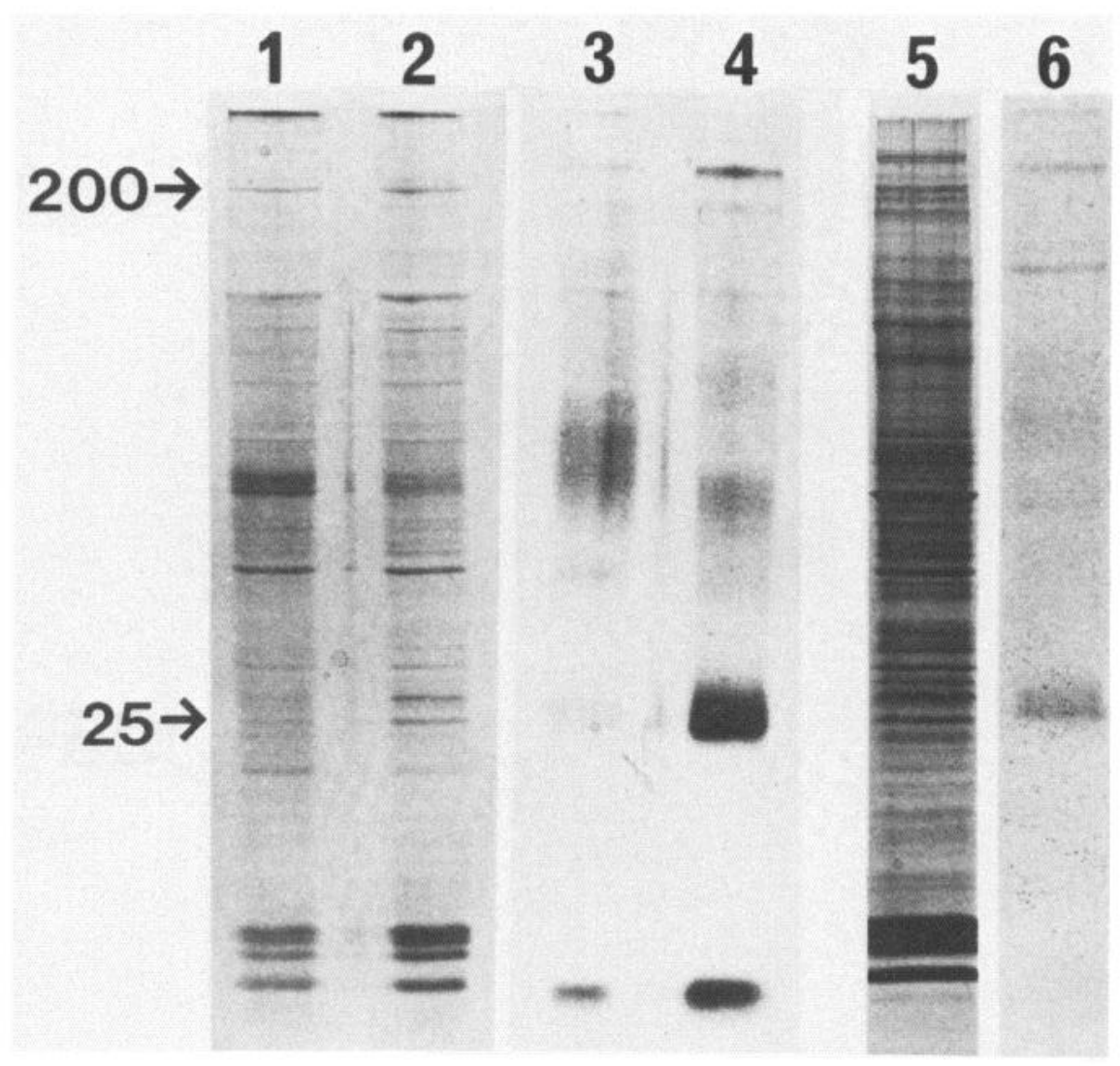

Figure 5. Association of the $M_{\mathrm{r}} \approx 25,000$ glycoprotein with the detergent-resistant cytoskeleton. PC12 cultures were labeled by 3 days of exposure to $\left[{ }^{3} \mathrm{H}\right]$ fucose. Lanes 1 and 2 represent the Coomassie blue-stained patterns of detergent-resistant cytoskeletons prepared from cells untreated (lane 1 ) or treated (lane 2) for 1 week with NGF. Lanes 3 and 4 show fluorographs of lanes 1 and 2 , respectively. Lane 5 shows the Coomassie blue-stained pattern of a nuclear fraction derived from NGFtreated $\mathrm{PC} 1$ cells, and lane 6 shows the corresponding fluorograph. The numbers of TCA-precipitable counts per minute loaded in lanes 3,4 , and 6 were 1500,1500 , and 400 , respectively. Numbers on the left indicate apparent $M_{r}\left(\times 10^{-3}\right)$ as derived from markers.

NGF treatment) were metabolically labeled with $\left[{ }^{3} \mathrm{H}\right]$ fucose, and immunoprecipitates of the cell extracts were obtained using Thy-1.1 monoclonal antibodies and protein A-Sepharose. Analysis by SDS-PAGE revealed the only specifically immunoprecipitated component to be a band which co-migrated with the $M_{\mathrm{r}} \approx 25,000$ glycoprotein in the corresponding cellular extract (Fig. 8). In addition, comparison of immunoprecipitates from cultures treated with or without NGF revealed a significant increase in levels of Thy-1 in the NGF-treated cells (Fig. 8).

The effect of NGF on the labeling of Thy-1-cross-reactive material with fucose could represent an enhancement of glycosylation or, alternatively, could reflect a selective increase in synthesis of the protein itself. To explore this, PC12 cells (with and without 6 days of NGF treatment) were exposed to $\left[{ }^{35} \mathrm{~S}\right]$ methionine for $4 \mathrm{hr}$ and equal numbers of incorporated counts were subjected to immunoprecipitation with monoclonal antiThy-1.1. As shown in Figure 9, electrophoretic analysis of the immunoprecipitates revealed that the NGF-treated cultures showed a significant increase in relative levels of ${ }^{35} \mathrm{~S}$-labeled Thy-1-cross-reactive protein. Additional experiments (not shown) revealed that exposure of PC12 cells to actinomycin-D $(10 \mathrm{ng} / \mathrm{ml})$ or camptothecin $(0.5 \mu \mathrm{g} / \mathrm{ml})$ during a 3-day metabolic label with $\left[{ }^{3} \mathrm{H}\right]$ fucose suppressed the effect of NGF on the $M_{\mathrm{r}} \approx 25,000$ glycoprotein. These findings indicate that NGF enhances the synthesis of Thy-1-cross-reactive protein and does so via a transcription-dependent mechanism.

\section{Discussion}

Regulation of the $M_{\mathrm{r}} \approx 25,000$ glycoprotein by NGF. The morphological and physiological alterations exhibited by PC12 cells after their exposure to NGF are accompanied by only a limited number of changes in protein and glycoprotein composition (McGuire et al., 1978; Garrels and Schubert, 1979). Two major glycoproteins are selectively enhanced in labeling during NGF-stimulated differentiation. One is a high molecular weight $\left(M_{\mathrm{r}} \approx 230,000\right)$ surface component, designated the NILE glycoprotein, which has been found to be a central and peripheral neuronal marker (Salton et al., 1983). The second, a low molecular weight glycoprotein of apparent $M_{\mathrm{r}} \approx 25,000$, is the subject of the present communication. In contrast to NILE glycoprotein, the $M_{\mathrm{r}} \approx 25,000$ glycoprotein was not removed from cells by trypsin treatment, and stimulation of labeling in response to NGF was detectable within 1 to 2 days. The increase of the $M_{\mathrm{r}} \approx 25,000$ glycoprotein did not parallel the time course of appearance and outgrowth of neurites. Several other changes in PC12 cell composition appear to precede extensive neurite outgrowth, including induction of acetylcholinesterase activity (Rieger et al., 1980) and increased synthesis of the p80 protein (McGuire and Greene, 1980).

As is the case for the NILE glycoprotein and several other proteins (see Greene and Tischler, 1982, for review), NGF appears to affect the labeling of the $M_{\mathrm{r}} \approx 25,000$ glycoprotein by selectively enhancing its synthesis and to do so via a transcription-dependent mechanism. The means by which NGF affects protein synthesis is unclear but, as judged by the lack of effect of EGF or dibutyryl cAMP, appears to be relatively specific and not to involve cAMP as a "sufficient" second messenger.

Identity of the $M_{\mathrm{r}} \approx 25,000$ component. Immunochemical evidence indicated that the NGF-modulated $M_{\mathrm{r}} \approx 25,000$ glycoprotein is identical to, or cross-reactive with, the Thy-1.1 antigen. The presence of Thy-1 antigen in brain and thymus has been described in many studies (cf. Williams et al., 1975; Morris et al., 1980; and Williams and Gagnon, 1982, for references). This antigen is expressed by a variety of neural cell types, including neurons, but not by certain glial cells (Mirsky and Thompson, 1975). Thy-1 has also been identified on a number of clonal cell lines of neuronal origin including PC12 cells (Morris et al., 1980). The precise biological function of Thy-1 in the nervous system is not clear, but since it increases 

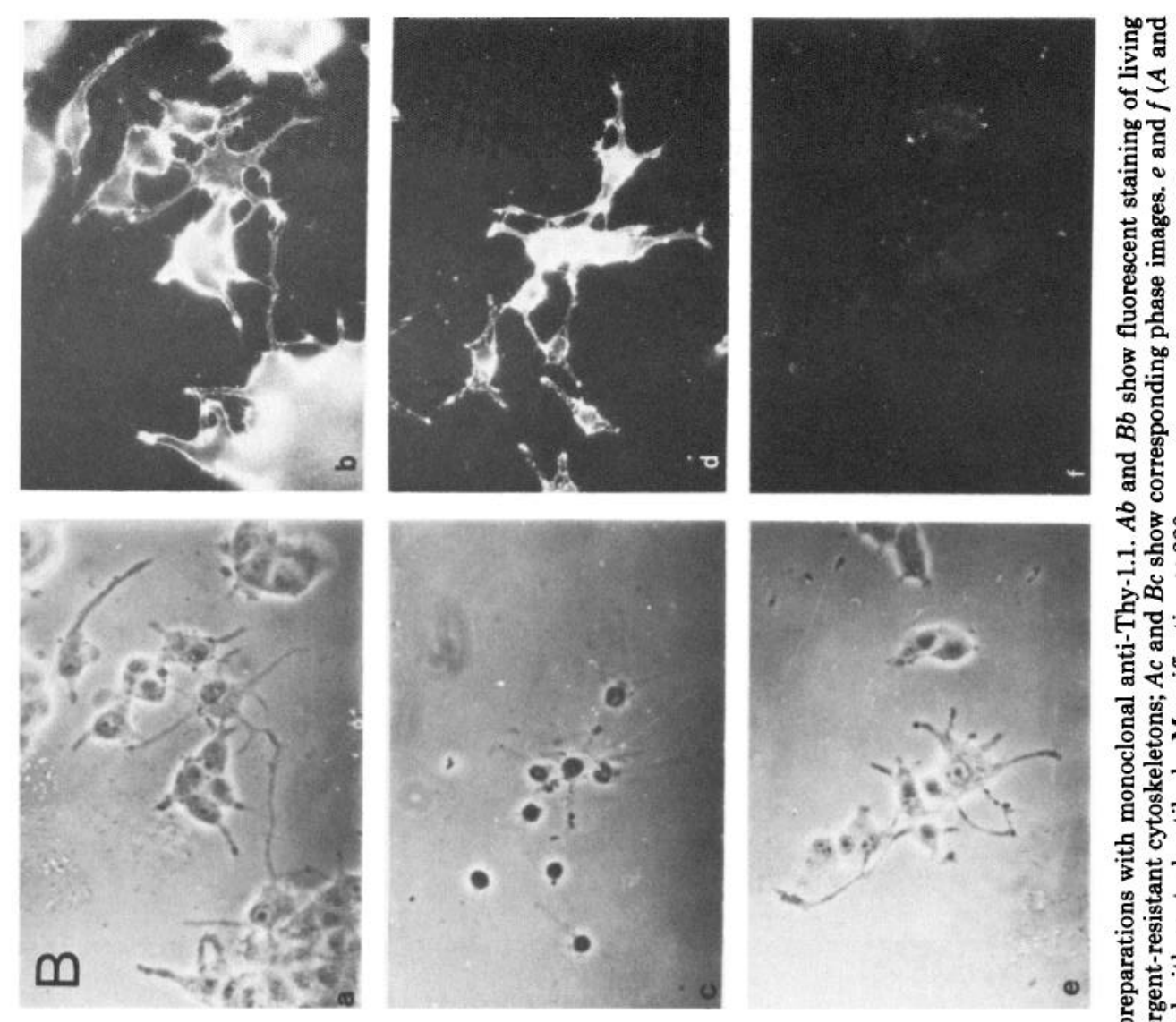

ชำ ชิ่

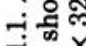

政

实司

它

范需

ฮี ถึ

잉

용

돈

능혀

竞.

迎苍落

\%

它

ब实
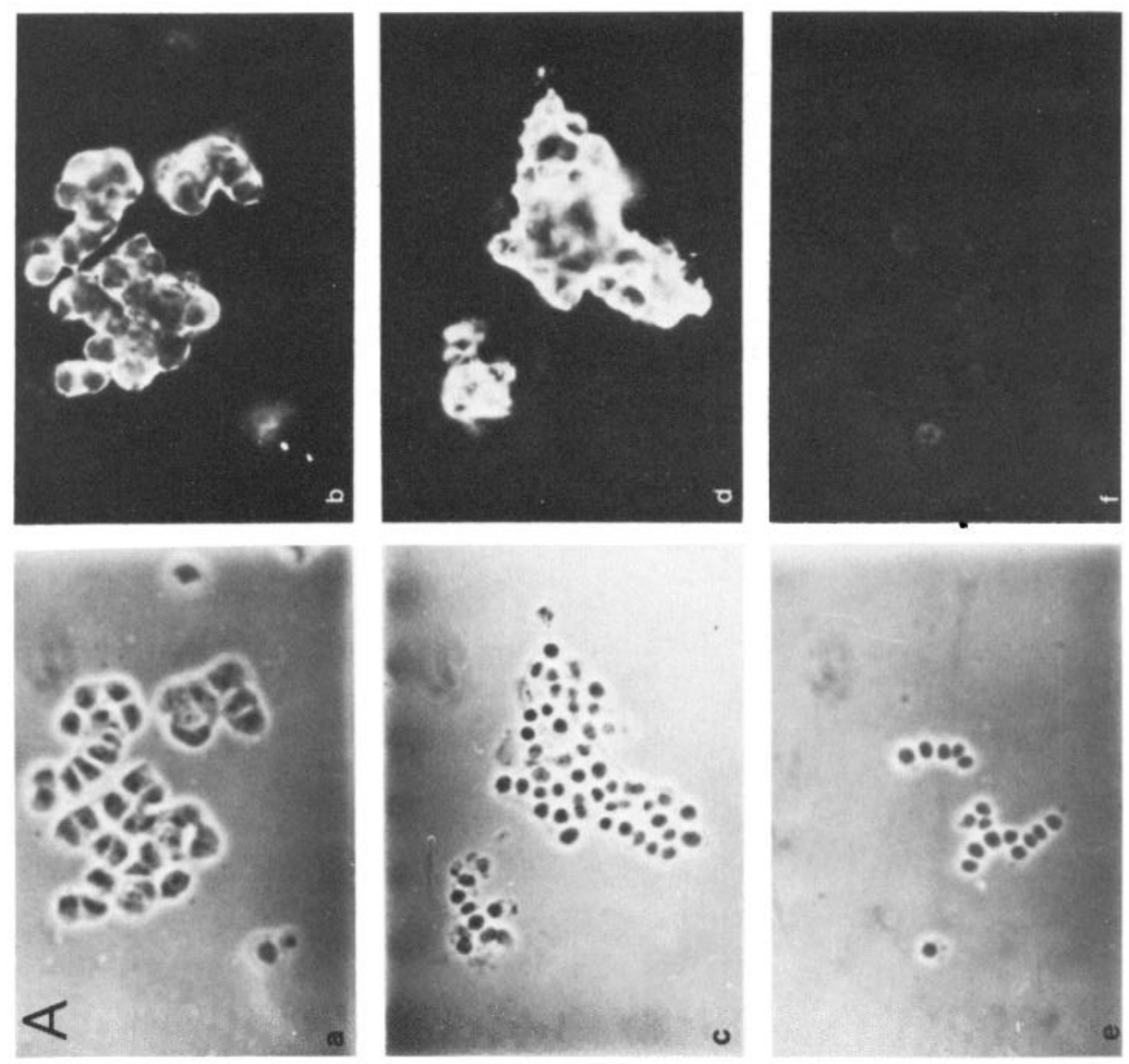

겅 응

용용

의 के

㺼莟

究范

덩롬.

$Z$ 난

密㻤

ต่ํํㅇ

둘흉

उٓ유

实

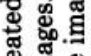

.

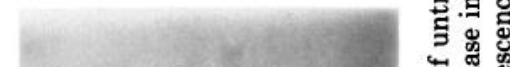

范

so

क्ष

范

速

总

동 동

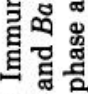

워

누

足卷㐫 

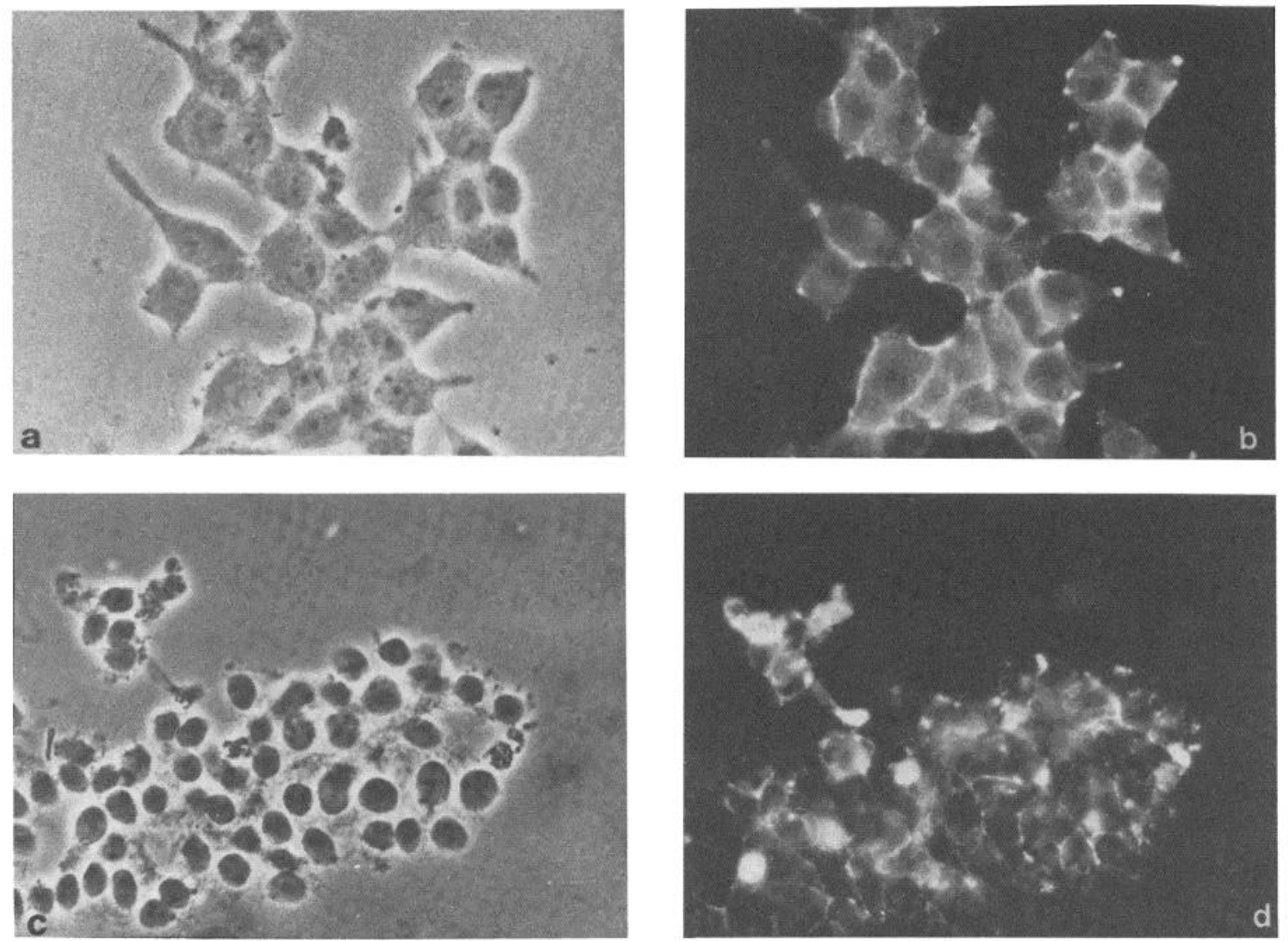

Figure 7. Labeling of PC12 cells with FITC-conjugated lentil lectin. $a$ and $b$ show phase and corresponding fluorescence images, respectively, of stained, living PC12 cells pretreated for 3 days with NGF. $c$ and $d$ show phase and corresponding fluorescence images, respectively, of stained detergent-resistant cytoskeletons prepared from NGF-untreated PC12 cells. Labeling was as described under "Materials and Methods." Magnification $\times 460$. 


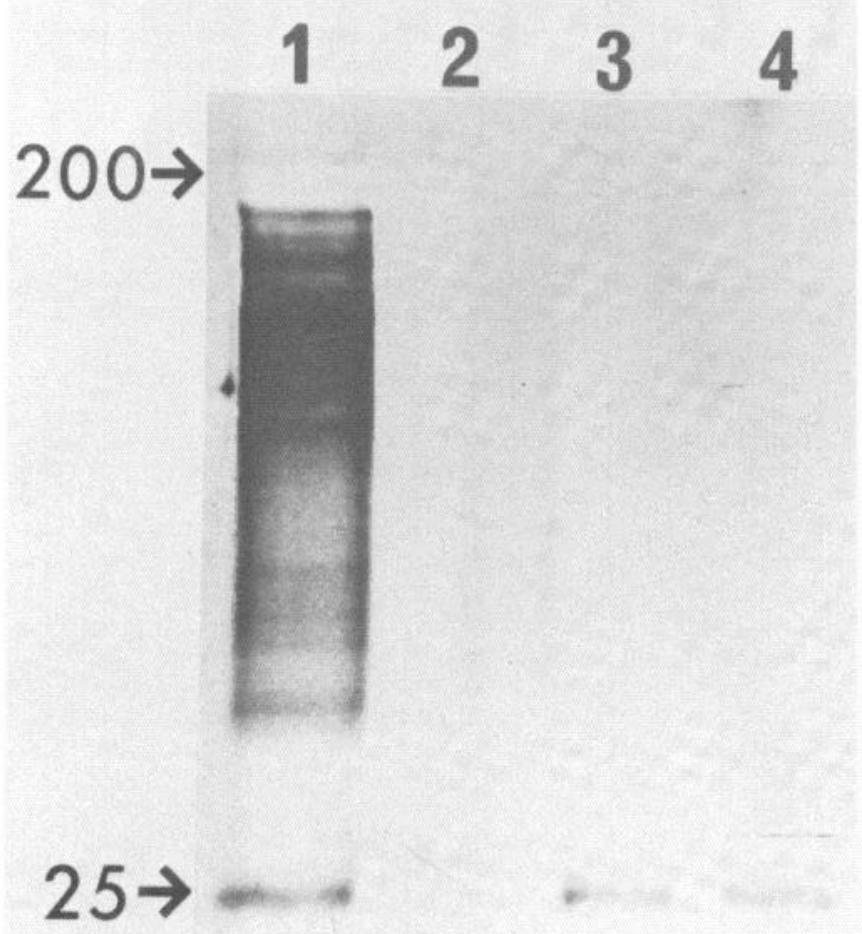

Figure 8. Indirect immunoprecipitation of $\left[{ }^{3} \mathrm{H}\right]$ fucose-labeled $\mathrm{PC} 12$ cell extracts with monoclonal anti-Thy-1.1. PC12 cultures were treated for 0,3 , or 6 days with NGF. $\left[{ }^{3} \mathrm{H}\right]$ fucose was present during the 3 days before harvesting. Equal numbers of TCA-precipitable counts per minute $(50,000)$ were subjected to indirect immunoprecipitation as described under "Materials and Methods," and the entire immunoprecipitates were analyzed by SDS-PAGE and fluorography. Samples are as follows: total cell extract (prepared in $2 \%$ Triton X-100) of cultures treated for 6 days with NGF (lane 1); immunoprecipitates from cells grown without NGF (lane 2), or with NGF for 3 (lane 3) or 6 (lane 4) days. A control immunoprecipitate carried out with a preimmune IgG showed no detectable bands. Numbers on the left idicate the $M_{\mathrm{r}}(\times$ $10^{-3}$ ) of standards.

in mouse and rat brain between birth and the first 4 to 5 postnatal weeks, a role for this glycoprotein in neural development seems probable.

Localization and cytoskeletal association of the $M_{\mathrm{r}} \approx 25,000$ glycoprotein. The present data suggest several features of the disposition of the $M_{\mathrm{r}} \approx 25,000$ glycoprotein in PC12 cells. First, immunohistochemical staining of intact, living cells with antiThy-1.1 indicates that this component is exposed on the cell surface. Second, $M_{\mathrm{r}} \approx 25,000$ glycoprotein was significantly enriched in Triton X-100-extracted cell fractions. It has been shown with various types of cultured cells that gentle extraction with Triton X-100 leads to extensive solubilization of cellular membranes and the removal of lipids and soluble proteins (cf. Ben-Ze'ev et al., 1979). This procedure leaves attached to the culture dish cell nuclei and the surrounding cytoskeleton, which are covered by a surface sheet, or lamina. As judged by phase microscopy, the fraction obtained after extraction of PC12 cells with $0.5 \%$ Triton X-100 appeared to possess these properties. This lamina is reported to appear as a continuous sheet which retains some surface proteins and lectin-binding sites (BenZe'ev et al., 1979). Association with the underlying cytoskeleton

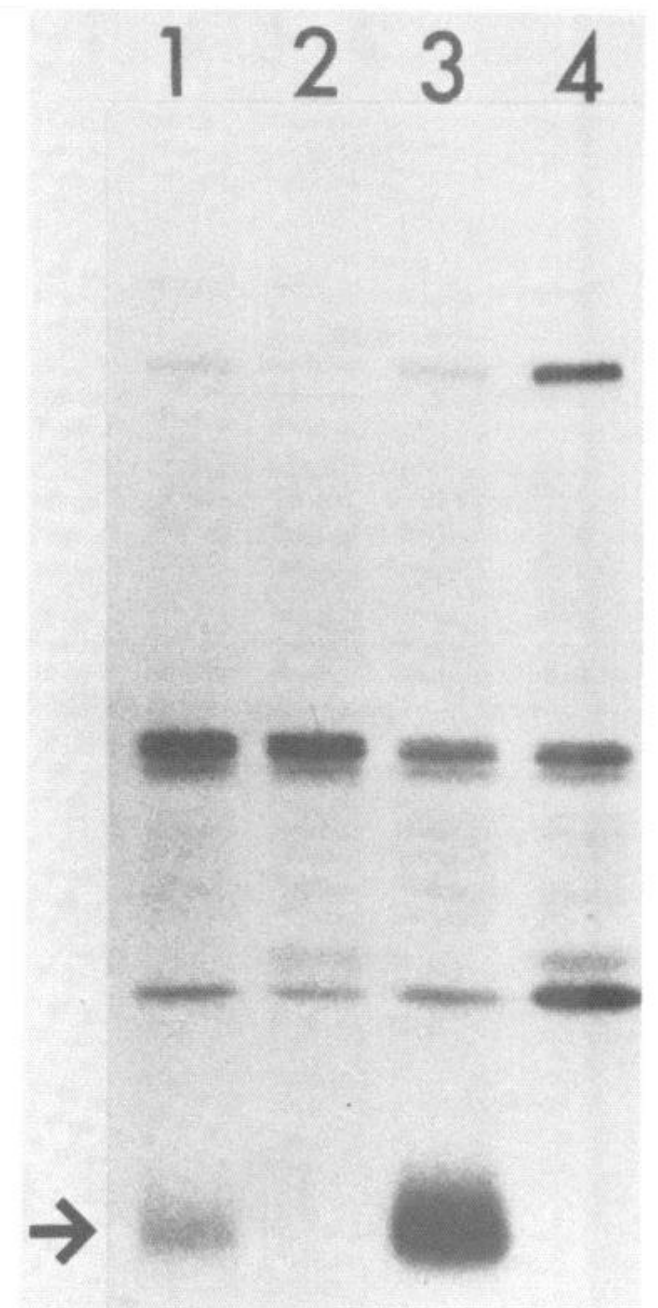

Figure 9. Indirect immunoprecipitation of $\left[{ }^{35} \mathrm{~S}\right]$ methionine-labeled $\mathrm{PC} 12$ cell extracts with monoclonal anti-Thy-1.1. Cultures were treated for 0 to 6 days with NGF and then exposed to $\left[{ }^{35} \mathrm{~S}\right]$ methionine for 4 $\mathrm{hr}$. The cells were extracted as described under "Materials and Meth ods," and equal numbers of TCA-precipitable counts per minute were subjected to indirect immunoprecipitation with either monoclonal antiThy-1.1 or a control monoclonal preparation. The entire immunopre. cipitates were analyzed by SDS-PAGE and fluorography. Samples are immunoprecipitations carried out with anti-Thy-1.1 (lanes 1 and 3) or control monoclonal antibody (lanes 2 and 4 ) on cells either untreated with NGF (lanes 1 and 2) or NGF treated for 6 days (lanes 3 and 4). Numbers at the left indicate the $M_{\mathrm{r}}\left(\times 10^{-3}\right)$ of markers.

may be responsible for the resistance of these laminar surface components to Triton X-100 (Ben-Ze'ev et al., 1979). Fractionation of the Triton X-100-resistant fraction indicated that the $M_{\mathrm{r}} \approx 25,000$ glycoprotein is not present in the nucleus. Along with the apparent surface-accessible location of the $M_{\mathrm{r}} \approx$ $25,000 /$ Thy- 1 component in intact PC12 cells, these findings suggest association of this glycoprotein with the surface lamina.

It is of interest to note that, whereas many of the prominent 
surface glycoproteins on $\mathrm{PC} 12$ cells are spontaneously released into the culture medium, this is not so for the $M_{\mathrm{r}} \approx 25,000$ glycoprotein (Richter-Landsberg et al., 1984). Likewise, the releasable glycoproteins all appear to be Triton X-100 extractable whereas the $M_{\mathrm{r}} \approx 25,000$ glycoprotein is Triton X-100 resistant. It is therefore conceivable that association of the $M_{\mathrm{r}}$ $\approx 25,000$ glycoprotein with the surface lamina/cytoskeleton could underlie its lack of releasability.

Possible functional significance. The function of the $M_{\mathrm{r}} \approx$ $25,000 /$ Thy- 1 glycoprotein in the PC12 cell or in the nervous system is not presently clear. Since a selective increase in labeling of this component occurs in response to NGF, a possible role is indicated in the conversion by NGF of PC12 cells from a chromaffin cell-like phenotype to a sympathetic neuronlike phenotype. Since the $M_{\mathrm{r}} \approx 25,000 /$ Thy-1 glycoprotein is surface exposed and may be linked with the cytoskeleton, a conceivable function could be interaction of cells with substrate and/or other cells. With regard to this, addition of monoclonal anti-Thy-1 to $\mathrm{PC} 12$ cultures pretreated with $\mathrm{NGF}$ for 4 to 5 days resulted in retraction of neurites, increased cell clumping, and loss of adhesion (C. Richter-Iandsherg, unpublished observations).

In conclusion, the present findings demonstrate that a cell surface $M_{\mathrm{r}} \approx 25,000$, Thy-1-cross-reactive glycoprotein is regulated by NGF. This marker will be valuable for studying NGF's mechanism of action. Conversely, the presence of this component in PC12 cultures and its modulation by NGF may be especially useful for studies of function.

\section{References}

Barclay, A. N., M. Letarte-Muirhead, A. F. Williams, and R. A. Faulkes (1976) Chemical characterization of the Thy-1 glycoproteins from membranes of rat thymocytes and brain. Nature 263: 563-567.

Barde, Y. -A., and H. Thoenen (1980) Physiology of nerve growth factor. Physiol. Rev. 60: 1284-1335.

Barondes, S. H. (1976) Neuronal Recognition, Plenum Press, New York

Ben-Ze'ev, A., A. Duerr, F. Solomon, and S. Penman (1979) The outer boundary of the cytoskeleton: A lamina derived from plasma membrane proteins. Cell 17: 859-865.

Garrels, J. I., and D. Schubert (1979) Modulation of protein synthesis by nerve growth factor. J. Biol. Chem. 16: 7978-7985.

Goldman, B. M., and G. Blobel (1978) Biogenesis of peroxisomes: Intracellular site of synthesis of catalase and uricase. Proc. Natl. Acad. Sci. U. S. A. 75: 5066-5070.

Greene, L. A., and E. M. Shooter (1980) The nerve growth factor: Biochemistry, synthesis and mechanism. Annu. Rev. Neurosci. 3: 353-402.

Greene, L. A., and A. S. 'Tischler (1976) Establishment of a noradrenergic clonal line of rat adrenal pheochromocytoma cells which respond to nerve growth factor. Proc. Natl. Acad. Sci. U. S. A. 73: $2424-2428$.

Greene, L. A., and A. S. Tischler (1982) PC12 pheochromocytoma cultures in neurobiological research. Adv. Cell. Neurobiol. 3: 373-
414.

Huff, K., D. End, and G. Guroff (1981) Nerve growth factor induced alteration in the response of $\mathrm{PC} 12$ pheochromocytoma cells to epidermal growth factor. J. Cell Biol. 88: 189-198.

Laemmli, U. K. (1970) Cleavage of structural proteins during the assembly of the head of bacteriophage T4. Nature 227: 680-685.

Laskey, R. A., and A. D. Mills (1975) Quantitative film detection of ${ }^{3} \mathrm{H}$ and ${ }^{14} \mathrm{C}$ in polyacrylamide gels by fluorography. Eur. J. Biochem. 56 . $335-341$.

Letarte-Muirhead, M., A. N. Barclay, and A. F. Williams (1975) Purification of the Thy-1 molecule, a major cell surface glycoprotein of rat thymocytes. Biochem. J. 151:685-697.

Levi-Montalcini, R., and P. U. Angeletti (1968) Nerve growth factor Physiol. Rev. 48: 534-569.

McGuire, J.C., and L. A. Greene (1980) Nerve growth factor stimulation of specific protein synthesis by rat $\mathrm{PC} 12$ pheochromocytoma cells. Neuroscience 5: 179-189.

McGuire, J. C., L. A. Greene, and A. V. Furano (1978) NGF stimulates incorporation of fucose or glucosamine into an external glycoprotein in cultured rat PC12 pheochromocytoma cells. Cell 15: 357-365.

Mirsky, R., and E. J. Thompson (1975) Thy-1 (Theta) antigen on the surface of morphologically distinct brain cell types. Cell 4:95-101.

Mobley, W. C., A. Schenker, and E. M. Shooter (1976) Characterization and isolation of proteolytically modified nerve growth factor. Biochemistry 15 : 5543-5551.

Morris, R. J., P.E. Mancini, and S. E. Pfeiffer (1980) Thy-1 cell surface antigen on cloned nerve cell lines of rat and mouse: Amount, location and origin of the antigen on the cells. Brain Res. 182: 119-135.

Osborn, M., and K. Weber (1977) The detergent-resistant cytoskeleton of tissue culture cells includes the nucleus and the microfilamant bundles. Exp. Cell Res. 106: 339-349.

Richter-Landsberg, C., V. M. Lee., S. R. J. Salton, M. L. Shelanski, and L. A. Greene (1984) Release of the NILE and other glycoproteins from cultured PC12 rat pheochromocytoma cells and sympathetic neurons. J. Neurochem, 43: 841-848.

Rieger, F., M. L. Shelanski, and L. A. Greene (1980) The effects of nerve growth factor on acetylcholinesterase and its multiple form in cultures of rat PC12 pheochromocytoma cells: Increased total specific activity and appearance of the $16 \mathrm{~S}$ molecular form. Dev. Biol. 76: 238-243.

Salton, R. J., C. Richter-Landsberg, L. A. Greene, and M. L. Shelanski (1983) Nerve growth factor-inducible large external (NILE) glycoprotein: Studies of a central and peripheral neuronal marker. J Neurosci. 3: $441-454$.

Schubert, D., M. LaCorbiere, C. Whitlock, and W. Stallcup (1978) Alterations in the surface properties of cells responsive to nerve growth factor. Nature 273: 718-723.

Truding, R., M. L. Shelanski, M. P. Daniels, and P. Morell (1974) Comparison of surface membranes isolated from cultured murine neuroblastoma cells in the differentiated or undifferentiated state. J. Biol. Chem. 249: 3973-3982.

Williams, A. F., and J. Gagnon (1982) Neuronal cell Thy- 1 glycoprotein: Homology with immunoglobulin. Science 216: 696-703.

Williams, A. F., A. N. Barclay, M. Letarte-Muirhead, and R. J. Morris (1975) Rat Thy-1 antigens from thymus and brain: Their tissue distribution, purification, and chemical composition. Cold Spring Harbor Symp. Quant. Biol. 41: 75-81. 